\title{
Quality assurance in the provision of language education and training (case study: language education policy)
}

\author{
A.R. Nurutdinova ${ }^{1 *}, D . S h$. Shakirova ${ }^{2}$, and E.V. Dmitrieva ${ }^{3}$ \\ ${ }^{1}$ Kazan (Volga Region) Federal University, Kazan, Russia \\ ${ }^{2}$ Kazan (Volga Region) Federal University, Kazan, Russia \\ ${ }^{3}$ Kazan State Power Engineering University, Kazan, Russia
}

\begin{abstract}
The purpose of this scientific article is to describe the practice of forming the university's language education policy as a factor in ensuring the professional training quality of modern specialists. The analyzes presented in the scientific article are intended for teachers, teachers of foreign languages, specialists in the field of professional education of various profiles, organizers of the educational process at universities, students, undergraduates, graduate students, applicants, representatives of university and non-university communities interested in: 1) quality assurance professional training of modern specialists at universities; 2) ensuring the language education quality of specialists of various profiles as a component and the quality indicator of professional education of specialists; 3) the language interaction and professional education as a system and subsystem of university education; 4) scientific disciplines integration: theory and methods of vocational education, pedagogy, didactics, politics, professional linguodidactics, methods of foreign languages teaching; 5) the relationship and interdependence of different policies (language policy, university's language education policy, quality policy) and different politics (world, European, state, regional, institutional/ university); 6) the concepts relationship and the mutual influence of the formation processes of the educational space of different levels, the university's educational environment, the educational context of the interaction of subjects, the linguistic educational environment; 7) theory and practice of the university's language education policy.
\end{abstract}

\section{A problem statement}

Changes in the socio-economic, socio-political, socio-cultural nature that are taking place worldwide have the strong impact on the system of professional training of modern specialists at universities.

The system of higher professional education is in the continuous transformation and is called upon to respond politically in a comprehensive manner (regulatory, substantive, procedural) and adequately (based on understanding the current situation in education) to

* Corresponding author: prof-ped.gpa@mail.ru 
respond to the challenges and new requirements for professional training at universities, such as:

the need to integrate higher professional education in Russia into an international unified educational space, which requires conditions for academic, social and professional academic and students' mobility;

- internationalization and educational services;

- $\quad$ ensuring high quality professional education for competitive specialists.

The changes that are taking place are gradually being understood by the education, and the natural response to the globalization is the desire of university communities to maintain autonomy, universities' uniqueness in a multicultural world, the educational activities diversity and the increasing competition of institutions of higher education, which has been one of the reasons for the universities transformation into major scientific and educational production innovation complexes, preservation and culture expansion.

In the pedagogical and didactic aspects, it has become necessary to ensure the educational programs variability, diversify teaching models and meet the information quality demand for the communicational and professional culture as well as the search for a balance between the language specialists, educational subjects' interests and vocational education for the wide range of people interested in training university professionals: employers, parents, potential users of educational services.

With the current internationalization process in all the spheres of people's life, there has been a sharp increase in the demand for the language education quality as an integral part of the professional training, since specialists are required to have an independent knowledge of not only one but also two or three foreign languages, their ability to perceive and participate in multilingual and multicultural situations on an equal "equilibrium" through business, personal and professional communication (oral and written) with partners, colleagues. Also, the demands on the educational process, on all university professors are changing rapidly, this is due to the need to be able to navigate and respond to new challenges.

In the context of the diversity, multifunctional and specificity of educational and pedagogical activities, the ongoing changes taking place in the educational environment at all levels, the political context of the higher vocational education system is being shaped, and the importance of educational policy at all levels, dimensions and its component, such as the phenomenon as language education policy, little studied in pedagogical science, is growing.

\subsection{The objective of the work}

The need to turn to educational policy arises in a context of change, contradiction and challenge, therefore, with the higher professional education system transformation and with a view to ensuring a high quality of education, the role of educational policy is more important than ever, but it is understood various ways: an effective means of resolving controversies in education (V.I. Soldatkin), seeking balance (D. Brauer, J. Toubon), discussion, debate, activity (E. Holtmann), process, meeting challenges and problems (K. Rohe), the different interaction of interest groups, the totality of subjective positions (I.D. Fromin), the measures (N.D. Galskova), strategy, development, solution and others.

Research objectives:

- to make a systematic transformational processes analysis in higher professional education, to formulate the main challenges of the time, to highlight trends and contradictions in higher professional education;

- to find out ways to ensure the quality of higher professional education in universities as a response to the challenges of the time; 
- $\quad$ substantiate the position that language education is a component and indicator of the quality of professional, if it is focused on the growth of the professional significance of language education, the development of language education as a component of vocational education, the language educational environment as a component of the educational environment of the university, foreign language competence as a component of professional competence in all levels of its formation (key, basic, special);

- $\quad$ to study the place of the university's language educational policy in the system of concepts about education;

- to substantiate the essence of the formation of the university's language educational policy as a factor in ensuring the quality of professional training of modern specialists;

- to substantiate and describe the formation principles of the university's language educational policy as a factor in ensuring the quality of professional training of modern specialists;

- to carry out the practical implementation of the formation concept of the university's language educational policy and describe the fragments of its practical implementation at the university in accordance with the three stages of formation: awareness, consultation and agreement.

The research problem is how to form the university language educational policy adequate to the modern challenges and the requirements for the quality education, capable of regulating the language interaction and professional education and ensure the quality of professionally significant language education of modern specialists.

The problem statement determined the purpose of the study - the research concept and formation model of the university's language educational policy as a factor in ensuring the quality of professional training of modern specialists.

The research object is the language education of modern specialists in the system of higher professional education.

The research subject - the formation concept of the university's language educational policy as a factor in ensuring the quality of professional training of modern specialists and the ways of its implementation.

\section{Results of the research}

The research hypothesis is based on the assumption that the university's language education policy ensures the quality of professional training of modern specialists if:

- $\quad$ revealed the essence, concept and specificity of the language educational policy formation of the university, established a connection with the language and educational policy of different levels;

- $\quad$ substantiated its functional role as a tool for targeted and multichannel impact on the language education quality;

- the boundaries of its use in the system of higher professional education of modern specialists at the university level have been determined;

- its adequacy to the changes in the state educational policy taking place in the process of forming a single educational space at the international, state and other levels has been established;

- the principles of the university's language educational policy formation and the content of the modern educational and language policy of different levels (world, European, federal, regional, university) are determined and substantiated;

- a model of the university's language educational policy has been developed, which ensures the quality of professional training of modern specialists, the stages of its implementation have been projected, the mechanism of formation has been presented. 
The following methods have been used:

- Theoretical: analysis of national and foreign scientific literature, study and use of the methodology of leading scientific directions, comparative analysis, system analysis, methods of logic theory, methods of design and forms of modelling, generalization;

- Empirical: sociological research, questionnaire, interview, interview, testing, data collection via computer support system «Monitoring the quality of foreign language learning», data visualization through graphs and diagrams, testing, presentations, experimental, experimental and experimental work in variable conditions, method of expertise, methods of attribute and quantitative analysis of quality, transfer and testing of ideas of qualitative models in education of specialists of different profiles, diagnostics of products of activity, Validation of the conceptual basis for the establishment of the language education policy of the university in the commercial educational activities of the university, in advanced training courses and in methodological seminars for university and school teachers; In the various levels of study models for full-time and part-time students, postgraduate students and candidates, bachelors, specialists and masters, the different age groups of the city and the region, and the various centres for teaching foreign languages in the city of Kazan, in individual and mini-group activities, in innovative educational projects and other types of educational activities;

- Statistical: statistical processing, computer processing through a monitoring system, interpretation of monitoring data, mathematical analysis, comparative analysis of testing data, processing and interpretation of statistical data sets of sociological research.

On the basis of the theoretical and practical assumptions, which show the need for a university's language education policy, describe the nature of its formation as a factor ensuring the training quality of modern specialists. In accordance with the main objective, the paper presents the materials of the study, answering to the following questions:

- What is common in the process of shaping the university's language education policy and the educational processes;

- What is the nature of the university's language education policy, as opposed to other types and levels of politics;

Whether there are general principles and provisions for the formulation of the university's language education policy;

- Which can be considered as a valuable basis for the presentation of the guiding principles of the university's language education policy;

- Under what conditions the university's language education policy is formed;

- what is the definition of the university's language education policy;

- what should be taken into account when developing the model, stages and descriptions of the mechanism for forming the university's language education policy.

General features of the development of the professional training system of modern specialists in universities and the formation of the university's language education policy are as follows:

1. Unity of humanitarian (including linguistic) education and professional training, socio-cultural orientation of education, cultural diversity, regionalization, systematism, multifunctionality, integrity of the educational system in diversity, the multitude of qualities of professional training of modern specialists are features of modern education of specialists and attributes of formation of university's language education policy.

2. Improvement of the quality of higher professional education, training of a competitive and highly qualified professional, on the one hand, the training of specialists as representatives of national and regional cultures in the context of a multicultural world community, on the other, which is dictated by the globalization of the world community, which in turn, in the process of forming the language education policy of the university, is 
the reason for the search for cultural harmonization of the processes of studying languages, cultures and professions.

3. Universities' consolidation, university complexes establishment - a marked trend in education, a common feature of higher professional education in these conditions and in the shaping of the university's language education policy is the desire to preserve the integrity and uniqueness of the university's educational system, relation's coordination between the structural components university and constituent entities.

4. The professional importance of language education is increasing, which makes it necessary to harmonize among the subjects of university education and to take into account the views of the representatives of the extrauniversity community in order to achieve as close as possible to the objective and result of the education of specialists, Therefore, the common feature of the vocational training of specialists and the formation of the language educational policy of the university is the orientation towards the purpose and result in the professional training and language education of specialists, and the goal is set accordingly as a result.

5. Higher professional education at universities is characterised as an open system, diversified in terms of levels of study, varied in programmes, models, technologies, nonlinear development, bifurcation and fluctuations, In other words, there are synergistic features inherent in the development of higher vocational education and, consequently, in the development of the language educational policy of the university as a pedagogical phenomenon in the university education system.

6. The system of professional training for specialists at the university needs to create conditions for self-improvement and self-fulfilment of the subjects of education, Improvement of the system of such conditions is a common feature of the development of modern university education and the formation of the university's language education policy.

7. The relevance of educational policies at all levels and of the university's language education policy is increasing, as many educational problems require policy solutions at all levels, including university education, Therefore, the common feature of the development of the system of professional training and the formulation of the language education policy of the university is the political nature of the solution of educational problems, First of all, ensuring the quality of the language education of specialists as an integral component and indicator of the quality of professional training of specialists.

8. In higher professional education, specialists identify structural, organizational, substantive and procedural aspects that relate to three dimensions of policy: regulatory, substantive and procedural. The general basis for the structural and functional components of university education and policy measurement is the set of values inherent in the educational system and in the language education policy of the university. A characteristic of the adequacy, complementarity of the components of the system and the political processes within it becomes common for the development of the system of professional training and the formation of the language educational policy of the university.

At the same time, there is a need to study the peculiarities of the university's language education policy, revealing such peculiar features of this pedagogical phenomenon that distinguishes it significantly from other types of policies (language, education, science and technology, quality policy) and levels (world, European, State, regional). On the basis of the studied theoretical scientific materials and practical prerequisites, it is possible to describe a whole range of provisions that make up a specificity, a set of special features of the formation of the language educational policy of the university. The specificity of the university's language education policy is reflected in the following:

1. The university's language education policy as a pedagogical phenomenon is found at the university level, bringing theory and practice of educational activities as close as 
possible to one another. No higher-level policy is closer to practical educational activity than the language education policy of the university. A special feature of the formation of the language education policy of the university thus becomes the maximum convergence of theory and practice of educational activity.

2. The absence of a systematic process of shaping the university's language education policy as a factor in ensuring the quality of the professional training of modern specialists leads to the non-assigned, Spontaneous actions in language education, as a component of the system of vocational training for up-to-date specialists, are leading to the discontinuation of language education from vocational education, which seriously undermines the quality of vocational training for specialists, Therefore, a special feature of the development of the language education policy of the university, which is a component of its specificity, Coordination between the representatives of the university community and the interaction of the system of vocational education of specialists with language education as a component of it becomes a matter of focus.

3. The absence of a scientifically sound conception of the formulation of the university's language education policy, and of principles and model for its formation at the university level, gives rise to the declarative nature of the normative and legal documents on State educational policy, International agreements, since in practice there is a vertical hierarchy of policies in a conceptual series, but there is no scientifically based level of university-language educational policy adequate to the requirements for modern vocational training of specialists. The scientific soundness and adequacy of legal and regulatory documents on education in the country and the world community are special features of the formation of the university's language education policy.

4. The purposeful, spontaneous and unsubstantiated resort to the university's language education policy results in the dysfunction of the Mini Language Education System, the loss of its strategy, and the disruption of even the very beautifully formulated mission of work, Work logic is not followed, available resources are wasted, purpose is confused with means, work is not systematically analysed, there is no satisfaction with the results of work, and there is disorientation in educational activities. The system of activity, strategy orientation and priorities are special features of the formation of language educational policy of the university.

5. The university's language education policy is designed as a purposeful search for a balance of interests among a wide range of persons interested in the quality of education of specialists. Coordination of actions is not episodic, but permanent. The success of the collective agreement is measured by understanding and agreeing on the objectives of results-based education programmes, educational models, special measures packages and activities. A special feature of the formulation of the university's language education policy is the constant coordination of the actions of the subjects of education, the result of which is the collegiate. A firm agreement documented in the university's comprehensive development programme, decisions of the scientific council, decisions of faculties, departments, councils of departments and methodical associations.

6. The language education policy of the University, as a factor in the training of modern specialists, is intended to promote the development of a quality policy at the University, the establishment of a management and quality assurance system at the University, For this purpose, the set of measures, decisions and actions within the framework of its formation is oriented on selection of positive experience of work in Russia and abroad, models of high quality of education are offered as a normative model, concept «quality» Explained and demonstrated to teachers, students, the public (broadcasting function), ongoing analysis of various educational activities (analytical function)The possibility of transfer and implementation of the best practices according to the actual 
conditions of a given educational institution is shown (transfer function). A special feature of the university's language education policy is its multifunctionality.

7. The language education policy of the university is aimed at implementing measures and creating systemic conditions for the continuous professional development of foreign language teachers and foreign language vocational education specialists. For this purpose, the possibilities of the Faculty of Advanced Studies are used, specialists of the specialized departments, departments of the University and the Rectorate are invited to speak, which leads to an understanding of the problems of language and vocational education in their interrelationship, the interaction of the system and subsystem, the search for joint solutions, arrangements and reflexions of activities. In this case, a specific feature of the language education policy of the university is the promotion of the professional development of teachers of foreign languages and specialists at the university, Members of the university community are aware of the interaction between language and vocational education.

8. The language education policy of the university is designed to seek not only the expressed potential for improving the quality of education, but also the internal, implicit and potentially available resources in the personnel, teaching system, didactic subsystem, educational processes, the structure of the units dealing with specialist language education. The constant search for reserves, potential in the system, processes, management and personnel is an integral part of the university's language education policy.

9. The language education policy of the university is to study the possibilities of introducing innovations in language education as a component of vocational education in accordance with the conditions of the specific university complex. Innovation today can become traditional tomorrow, innovation for one institution is not an innovation for another, so it is necessary to take into account the specific needs, capacities, conditions and specificities of individual institutions, to offer such innovations, which can really and really be introduced in a specific collective of teachers and students, which are partially or fully tested, demanded, calculated, reasoned, accepted by the collective, the collective is ready for their introduction, Since it accepts them positively and is aware of their importance and necessity. In formulating the university's language education policy, it should be borne in mind that it often takes a certain period of time to understand and understand the need for change and innovation. Scientific and innovative developments are «staple» elements of the language education subsystem, cannot be considered independently from other elements of the subsystem and components of the whole system. In this case, the development of the language education policy of the university is characterized by the introduction of innovations based on the identity, possibilities and conditions of the changing university complex.

10. The university's language education policy is harmoniously integrated with the university's educational content and quality policy, with a multi-channel impact on the next components of the mini-language education system as part of the macro-education systems: on the structural and organizational component and its management, the content and organizational processes therein, the scientific innovation and development therein, the consolidation and regulation and the interaction therein of actors. The mission of shaping the university's language education policy is to promote the greatest possible convergence of vocational and language education through a continuous dialogue between the university and extrauniversity communities, which ultimately leads to the quality of professional training through a multi-channel impact on the quality of the language and professional training of specialists. A special feature of the university's language education policy is its dialogue and multi-channel impact on the development of the quality of education. 
11. Analysis, search, orientation, coordination of interests, regulation, introduction, stimulation, execution and implementation - attributes of the formation of the language educational policy of the university.

12. The language education policy is aimed at studying the explicit and implicit reserves for ensuring the quality of professional and relevant language education for future professionals, and is constantly analysing the resources, conditions and content of education, At the same time, it acts as an attributor to the self-regulation of the language education system as part of the professional and self-development of the pedagogical system and the didactic subsystem, The establishment of conditions for the university's linguistic educational environment for the self-empowerment and self-improvement of teachers and future specialists. A special feature of the formation of the language education policy of the university in these conditions becomes the ability to exert influences that stimulate self-improvement, self-regulation and self-realization of the elements of the subsystem and its subjects.

13. The university's language education policy is not spontaneous, but purposeful. As a process, it has certain formative stages, the main ones being awareness, agreement and agreement. A special feature of the university's language education policy is its stagesetting.

14. The agreement is also seen as a result of the university's language education policy. On the basis of the agreement, the processes of realization of the collective of teachers and trainees conceived in scientific and educational activities are being developed. The implementation trajectory depends on the content of the agreement and can be adjusted directly in practice, and new harmonization and agreement may be necessary. A special feature of the university's language education policy is the desire for agreement, openness to correction and new harmonization.

15. The basic parameters for measuring the quality of education in accordance with the philosophy of the university's language education policy are the universal quantitative and attribute indicators of the various types and forms of educational activity, which are subject to analysis, submitted to the public, the analysis concludes that the measure is adequate or inadequate, effective or ineffective, sustainable or unsustainable, and the final determination of whether or not the measure is suitable, Actions, decisions, programmes, models, teaching technology, forms of work, services, processes, various types of educational activities, the language educational policy of the university itself.

An analysis of the general features of the development of the system of higher professional education of specialists and the formation of the language educational policy of the university, as well as of the special features of the formation of the language educational policy of the university shows: That the process of shaping the language education policy of the university is characterised by a number of values that make it possible to consider this pedagogical phenomenon as an ongoing process, a purposeful activity, a strategy, a methodological reference point and a pedagogical phenomenon, impulse to change, phenomenon of political pedagogy, form of policy of analytical type, «tuning» achievement of pedagogical resonance, multifunctional attractor, translator of new ideas, way to answer challenges of time, necessity and possibility, source of quality, a tool for the convergence of language and vocational education, a method for the multi-channel impact on quality, technology for ensuring the quality of professionally relevant language education for specialists, quality control and guarantee, and quality assurance factor, which are common and special, systemic and procedural, diverse and peculiar, «poly» and «itself» conceptual, qualitative and quantitative, cultural and synergistic, explicit and implicit, traditional and innovative, the whole and private, theoretical and practical, priority and secondary. Singled out pairs of values of the concept of language educational policy of the university and the process of its formation allow to formulate a set of «cross-cutting» 
methodological principles of formation of language educational policy of the university, which permeate the whole process, they are constantly present at all stages of the formulation of the university's language education policy, and they show the conditions under which the university's language education policy is being developed as a factor in ensuring the quality of the vocational training of up-to-date specialists:

1. The principle of taking into account the general and specific nature of the university's language education policy is based on the general features of vocational and linguistic education and the special features of linguistic education;

2. The principle of systematization and procedure in higher vocational education makes it possible to observe the relationship between the structural components of the vocational training system and the elements of the language education subsystem and to improve the interaction processes with the subsystem as a macro-system and mini-systems;

3. The principle of respect for diversity and identity in education is a basis for recognizing the diversity and uniqueness of conditions, opinions, ideas, technologies, cultures, languages, models, etc. in the system of university education of specialists;

4. The principle of interaction of «poly» and «self-» concepts in education orients on taking into account polycultures in the world community and the process of selfidentification of a specialist as a carrier of national, regional, professional cultures, aims at self-regulation of the system, Self-improvement of the system and the self-realization of actors in the multicultural system, environment, space, university and extrauniversity communities;

5. The principle of the quality-quantity ratio is aimed at analysing both the attributive and quantitative indicators of the language and vocational training of specialists, and provides for the use of various forms of analysis of the improvement of the quality of education of specialists (monitoring, questionnaires, interviews, external and internal expertise, analysis of quality dynamics and other forms);

6. The principle of interaction between synergistic and cultural phenomena in education is aimed at taking into account synergistic concepts (openness of the system, selfdevelopment, non-linearity, fluctuation, bifurcation, self-regulation and others) and cultural concepts (cultural values, concepts, dialogue, language as a whole, intercultural communication, professional culture, communication and others) that take place in education and provide the scientific basis for the methodology of the process of formation of the language educational policy of the university;

7. The principle of studying explicit and implicit resources is aimed at studying and using the expressed and hidden reserves available in the system of university education of specialists: in the use of scientific approaches, in the improvement of structural organization, Development of the university's legal and regulatory framework, establishment of the conditions of the linguistic educational environment, development of the pedagogical system, the didactic subsystem, construction of educational processes, and study of the capabilities of staff, Use of international and domestic expertise in professional training and other educational activities;

8. The principle of combining traditional and innovative education of professionals provides the basis for preserving the best traditions of the university education system, while at the same time responding to new quality requirements, focusing on the renewal of education, Introduction of a new system to improve the quality of training;

9. The principle of balance between the integrity of the system and its parts is aimed at considering vocational and linguistic education as a whole and part of it, at improving their interaction, at maintaining a balance of interests and at organizing a dialogue among the subjects of education (organizers of the educational process, specialists of specialized structures, teachers of foreign languages, students), taking into account the opinions of representatives of the extrauniversity community; 
10. The principle of the interrelationship between theory and practice is present at all stages of the formulation of the university's language education policy, and practice is constantly accompanying theory and provides a basis for theoretical study; Theoretical provisions are tested in practice under different conditions, theory and practice are complementary, and theory and practice are inextricably linked in the formulation of the university's language education policy;

11. The principle of priority and secondary is used as a guide to defining primary and secondary education, to maintain the overall strategy of shaping the university's language education policy, to respect the mission, the creed, The basic values defined by the university community in language education as part of professional education, to regulate the relations of subjects, to take adequate decisions, to design educational processes, Environment, in accordance with the strategy, develop tactical and operational measures.

A sine qua non for the formulation of the university's language education policy is to ensure that its objective is consistent with the objectives of the university's educational policy and those of the State's educational policy. Questions of targeting are well studied and covered in the scientific literature of many subject areas: pedagogy, sociology, linguistics, methods of teaching foreign languages, psychology. A modern view of the issues of purposefulness in the formation of the university's language education policy focuses on increasing the focus on the effectiveness of the work, avoiding the mixing of means and objectives, and using principles of its formation that are life-sustaining a focus on continuous improvement, the ability to respond to the challenges of our time. In the face of emerging problems and contradictions in education, an analysis of the hidden possibilities of educational documents, regulations and materials at the university and supra-university levels is also required. Definition of objectives, objectives, means, means.

\section{Conclusions}

Education is often not a ready-made task, requiring further analysis, reflection and decision-making. Related to the search for the so-called hidden reserves of the legal and regulatory framework of the various levels of educational policy is the condition of the study, Analysis and use of the transferability of State documents in the process of formulating the language education policy of the university. In the global socio-political arena, the adoption of new decisions and their implementation in cooperation between States, individual regions and individuals have acquired value. Within the framework of the formulation of the university's language education policy, the context of the interaction of the subjects of education within the university and with the representatives of the extrauniversity community is becoming pivotal. The whole range of political actions is guided by the supreme objective - respect for each individual and for each subjective position. The humanism of the phenomenon under study consists in its orientation on a palette of different opinions, a culture of discussion, taking into account different points of view, seeking balance, balance and interaction of different subjective positions. The provision basis is a collective work, joint study and dissemination of universal and professional values in domestic and foreign education.

The university's language education policy is inseparable from the university's educational policy and the university's quality policy when it comes to the quality requirements of future professionals. The very times of political, social and economic change, powerful integration processes and the continuous transformation of the higher vocational education system call for the development of common strategic directions for different types of policies, and for coordination of actions, transparency of ideas, agreement on the objectives and content of education of specialists, harmonization of policies and actions in the educational environment of each individual university. 
The university's language education policy is influenced by the socio-economic and socio-political conditions at the supra-university levels, which are constantly changing, Therefore, the formation of a language education policy should be seen as a movement, as an ongoing process. With diversification and decentralization of education, there can be no rigid algorithm and no one-size-fits-all prescription. The language education policy of the university is formed on the basis of the choice of the optimal path, recognized as a result of the reconciliation of different opinions and subjective positions, implemented with the aim of ensuring the quality of professional training of modern specialists. The correct choice is confirmed by practice, therefore the formulation of the language education policy of the university is accompanied by practical implementation in the form of a test of the idea.

As a result of the analysis of the general and specific features of the university's language education policy, the values underlying it and the conditions for its formation, it is possible to formulate a definition of the university's language education policy:

The shaping of the university's language education policy is understood as a purposeful process of reflection;

- agreement among the participants in this process on activities to ensure the quality of professionally relevant language education for specialists, on the basis of respect for personal and subjective positions, taking into account the conditions of the university.

Thus, a theoretical analysis of the essence of the formation of the university's language education policy confirms the hypothesis that the language education policy of the university ensures the quality of professional training of modern specialists, if the concept and the specifics of its formation have been thoroughly explained, and its relationship with linguistic and educational policy at various levels has been established, the scientific basis for its role in ensuring the quality of language education as a component of the professional training of modern specialists. The process of the purposeful formulation of the university's language education policy is a tool that provides guidelines for educational activities, guides the forces that promote the quality of the professional training of specialists, and provides effective assistance to teachers, students and interested members of the university and extrauniversity communities.

\section{References}

1. A.R. Nurutdinova, D.P. Sheinina, V.R. Gagarina, M. Yousaf, Linguocultural specifity of phraseological units in the process of teaching languages, Rev. EntreLínguas, 7, 126-134 (2021)

2. A.R. Nurutdinova, O.V. Shelestova, I.V. Baez, Linguistic and didactic aspects of the "linguistic consciousness" formation in teaching foreign languages: grammar skills formation, Rev. EntreLínguas, 7, 105-114 (2021)

3. A.R. Nurutdinova, E.V. Dmitrieva, E.A. Nelyubina, L.R. Nurova, K.R. Wagner, The interactive education in teaching languages: microblogging as the way to improve postgraduate students' communicative interaction in English, XLinguae, 11/2, 120 135 (2018)

4. A.R. Nurutdinova, E.V. Dmitrieva. The challenges for english language instruction (approach and analyse): the educational and cultural concern, Achievements of modern science and education, 7, 143-147 (2017)

5. W.J. Clancy, Qualitative Students Model, Annuel Review of Computer Science. Annual Reviews inc., I, $381-450$ (1986)

6. L. Zailskaite-Jakšte, R. Kuvykaite, Implementation of Communication in Social Media by Promoting Studies at Higher Education Institutions, Eng. Econ., 23, 174-188 
(2012)

7. Y.S. Lincoln, S.A. Lynham, E.G. Guba, Paradigmatic controversies, contradictions, and emerging confluences, revisited, The Sage Handbook of Qualitative Research, 4, 97-128 (2011)

8. L.A. Schindler, S. Puls-Elvidge, H. Welzant, L. Crawford, Definitions of quality in higher education: A synthesis of the literature, Higher Learning Research Communications, 5(3), 3-13 (2015)

9. L. Harvey, The power of accreditation: views of academics, Journal of Higher Education Policy and Management, 26(2), 207-223 (2004)

10. J.C. Richards, T.S.C. Farrell, Professional development for language teachers, 130 (2015)

11. K.M. Anderson, M. Spooner, L.M. Calhoun, F. Spooner, Reviewing and refining: A professional education unit's journey toward accreditation, Teacher Education and Special Education, 30(2), 57-66 (2007)

12. D.J. O'Shea, D. Hammitte, R. Mainzer, M.D. Crutchfield, From teacher preparation to continuing professional development, Teacher Education and Special Education, 23(2), 71-77 (2000)

13. F.J. Troyan, Standards for foreign language learning: Defining the constructs and researching learner outcomes, Foreign Language Annals, 45(s1), 118-140 (2012) 